\title{
Diyetle Tuz Alımının Besin Tercihi ve Tüketimine Etkisi
}

\author{
Effect of Dietary Salt Intake on Food Preferences and Consumption
}

\author{
Büşra Turan Demirci' ${ }^{1}$, Zehra Büyüktuncer ${ }^{2}$
}

Geliş tarihi/Received: 15.11.2019 • Kabul tarihi/Accepted: 30.12.2019

\section{ÖZET}

Diyetle aşırı tuz alımının insülin direnci ve obezite gelişimi için risk oluşturabileceği belirtilmiş olmasına karşın, bu etkiyi nasıl oluşturduğuna yönelik mekanizmalar henüz net olarak açılanmamıştır. Potansiyel etki mekanizmaları arasında, diyetle aşırı tuz alımının şekerli içecek ve yağlı besin tüketimini teşvik ederek, pozitif enerji dengesine neden olması yer almaktadır. Özellikle çocuklarda diyetle fazla sodyum alımının susuzluğa neden olarak, diyet enerjisine önemli katkısı olan şekerli içeceklerin tüketimini arttırdığı gösterilmiştir. Ayrıca, tuz içeriğinin besinlerin lezzetini arttırarak onları iştah açıcı hale getirdiği ve bunun sonucunda da doygunluğu azaltarak enerji tüketimini ve aşırı yemeyi tetiklediği bildirilmiştir. Yüksek enerji içerikli besinlerde yağ ve tuzun yaygın şekilde iştah açıcı bileşim olarak kullanılması, tuz tüketimiyle diyetle yağ alımı arasında olası bir ilişki olduğuna işaret etmektedir. Bu derlemede, diyetle yüksek tuz alımının besin tercihi ve tüketimi üzerine etkileri incelenerek, tuz alımının azaltılmasını hedefleyen halk sağlığı politikalarına değişik bir bakış açısı sunulması amaçlanmıştır.

Anahtar kelimeler: Diyetle tuz alımı, şekerli içecek tüketimi, yağlı besin tüketimi, obezite riski

\section{ABSTRACT}

High dietary salt intake was reported as a risk factor in the development of insulin resistance and obesity, however, the mechanisms of this effect have not been clarified clearly yet. Potential mechanisms include high dietary salt intake, which promotes the consumption of sugar-sweetened beverages and fatty foods, leading to a positive energy balance. It has been shown that dietary intake of excess sodium, especially in children, leads to thirst and increases the consumption of sugarsweetened beverages, which have an important contribution to dietary energy. Furthermore, the salt content of foods increases their flavor and makes them appetizing, therefore, leads to decreasing satiety and overeating. The widespread use of fat and salt as an appetizing combination in foods with high energy content indicates a potential relationship between salt intake and dietary fat intake. In this review, it is aimed to present a different perspective on public health policies aiming to reduce salt intake by examining the effects of high dietary salt intake on food preferences and consumption.

Keywords: Dietary salt intake, sugar-sweetened beverage consumption, fatty food consumption, obesity risk

1. Hacettepe Üniversitesi Sağllk Bilimleri Fakültesi, Beslenme ve Diyetetik Bölümü, Ankara, Türkiye

가 https://orcid.org/0000-0001-5497-0887
2. İletişim/Correspondence: Hacettepe Üniversitesi Sağlık Bilimleri Fakültesi Beslenme ve Diyetetik Bölümü, Ankara, Türkiye

E-posta: hzbtuncer@hacettepe.edu.tr • $\odot$ https://orcid.org/0000-0002-2039-8568 


\section{GíRiş}

Diyetle fazla miktarda tuz alıminin hipertansiyon başta olmak üzere kardiyovasküler hastalıklar, inme, böbrek hastalıkları, osteoporoz ve bazı kanser türleri gibi çeşitli hastalıklar için önemli bir risk etmeni olduğu uzun zamandır iyi bilinmektedir $(1,2)$. Dünya Sağlık Örgütü (DSÖ) diyetle tuz alımının neden olduğu bu olumsuz etkilerden korunmak amacıyla günlük tuz alımının $5 \mathrm{~g}$ ile sinırlandirılması önerisinde bulunmaktadır (1). Buna karşın, dünya çapında tuz alımı genellikle önerinin üzerindedir. Birçok toplumda tuz alımının 9-12 g/gün ile önerilen maksimum alım miktarının iki katına ulaştığı bilinmektedir (2). Bu nedenle, hem ulusal hem de uluslararası programlar ile tuz tüketimin azaltılması amaçlanmaktadır (1,2). Diğer taraftan son yıllarda yapılan çalışmalar, diyetle fazla tuz alıminın etkilerinin sadece iyi bilinen bu hastalıklarla sınırlı olmadığını, tip 2 diabetes mellitus (tip 2 DM) ve obezite gibi beslenme ile ilintili kronik hastalıklar için de önemli risk etmeni olabileceğini göstermiştir $(3,4)$. Diyetle tuz veya sodyum alımının insülin direnci, obezite veya tip 2 DM gelişimindeki etkisinin olası mekanizmaları henüz tam olarak açıklanamamıştır (3). Yüksek sodyumlu diyetlerin enerji alımından bağımsız olarak, plazma leptin konsantrasyonunu ve adipozit hipertrofisini arttırarak beyaz adipoz dokunun lipojenik kapasitesinde artış sağlama gibi mekanizmalarla obeziteye neden olabileceğini gösteren hayvan modelleri mevcuttur $(5,6)$. Ek olarak, tuz alıminin besin tüketiminin kontrolünde rol oynayarak beslenme ile ilintili kronik hastalıklar için bir risk faktörü olduğu hipotezini destekleyen kanitlar da giderek artmaktadır $(7,8)$. $\mathrm{Bu}$ derlemede, diyetle yüksek tuz alımının besin tercihleri ve tüketimi üzerindeki etkisinin güncel literatür ışığında incelenmesi amaçlanmıştır.

\section{Diyetle Tuz Alımının Şekerli İçecek Tüketimi Üzerine Etkisi}

Şekerli içecekler diyetin en önemli eklenmiş şeker kaynaklarındandır ve genellikle büyük oranda yüksek fruktozlu misır şurubu içermektedirler. Günümüz Batı tarzı diyetinde, fruktoz kaynağı olan sükroz ve yüksek fruktozlu misır şurubu başta olmak üzere nişasta bazlı şekerlerin eski yıllara göre çok yüksek oranlarda tüketildiği gösterilmiştir (9). Artan tüketim obezite, tip 2 DM, kardiyovasküler hastalıklar, karaciğer yağlanması ve bazı kanser türleri gibi birçok hastalığın artan prevalansı ile ilişkilendirilmiştir (10). Dünya Sağlık Örgütü başta olmak üzere uluslararası birçok sağlık otoritesi tarafından bu gerekçe ile eklenmiş şeker tüketiminin sınırlandırılması yönünde öneriler geliştirilmiş olmasına karşın, bu hedef birçok toplum tarafından karşılanamamaktadır (11).

Son yıllarda yapılan çalışmalar, diyetle eklenmiş şeker alımının neden olduğu sağlık risklerinde diyetle tuz alımınin dolaylı yoldan rol oynayabileceğini göstermiştir (3,8). Diyetle fazla sodyum alımı, ekstraselüler sıvı hacmini artırmakta; baroreseptör ve natriüretik peptid stimülasyonu ile renin-anjiotensinaldosteron sistemi ve arjinin vazopressinin baskılanması sıvı hacminin dengelenmesini sağlamaktadır(12). Buhomeostatik dengeninsağlanma sürecinin çıktılarından biri susama hissinin artmasıdır $(12,13)$. Diyetle tuz alımının 1 g/gün azaltılmasının günlük sıvı tüketimini hipertansif bireylerde $65 \mathrm{~mL}$ ve normotansif bireylerde $69 \mathrm{~mL}$ azalttığı gösterilmiş; genel popülasyonda tuz alımı günlük 10 g’dan DSÖ önerisi olan 5 g’a düşürüldüğünde sıvı tüketiminin $350 \mathrm{~mL}$ azalacağı ve bu azalmanın beraberinde şekerli içecek tüketiminde de azalma sağlayacağı belirtilmiştir (13). Örneğin, Birleşik Krallık’ta sıvı tüketiminin \%25'ini şekerli içecekler oluşturmaktadır ve tuz tüketiminde hedeflenen azalma sağlandığında şekerli içecek satışlarında günde 13 milyon, yılda 5 milyar azalmanın sağlanabileceği beklenmektedir (13). Şekerli içecek tüketimi Birleşik Krallık’a göre daha fazla olan Amerika Bileşik Devletleri’nde tuz tüketimin azalması ile şekerli içecek pazarında yılda 40 milyarlık küçülme ön görülmektedir (13). Bazı şekerli içecek üreticilerinin yüksek tuz içeren atıştırmalık ürünleri de üretiyor olmaları bu açıdan değerlendirildiğinde iyi bir pazarlama stratejisi olabilir. 
Çocuk ve adölesanlarda yapılan çalışmalar, diyetle tuz alımı ile şekerli içecek tüketimi arasındaki sinerjik ilişkiyi desteklemektedir (14,15). Diyet alışkanlıkları ile obezite arasındaki ilişkinin araştırıldığı bir çalışmada, adölesanların şekerli gazlı içecek tüketimi ile yüksek tuz içeren fast-food besinleri ve tuzlu atıştırmalıkları tüketim durumları arasında önemli düzeyde pozitif ilişki olduğu saptanmıştır (14). Benzer şekilde, adölesanlarda tuz alımı ile hidrasyon durumu arasındaki ilişkinin incelendiği çalışmalarda 24-saatlik idrarla sodyum atımındaki artış şekerli içecekler dahil olmak üzere artan sıvı tüketimi ile ilişkilendirilmiştir $(15,16)$. Bu yaş grubunda yapılan ilk çalışmada, günlük tuz tüketiminde $1 \mathrm{~g}$ artış veya azalmanın şekerli içecek tüketiminde $27 \mathrm{~g}$ artış veya azalma ile sonuçlandığı gösterilmiştir (17). Bu

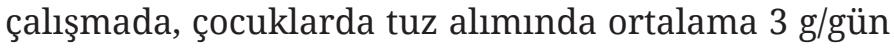
azalmanın şekerli içecek tüketimini haftada yaklaşık 2.3 porsiyon azaltacağl, bunun da $244 \mathrm{kkal} / \mathrm{hafta}$ daha az enerji alımı ile sonuçlanacağı ileri sürülmüştür. Tuz tüketimi ile ilgili önerilen bu değişimin çocukluk çağı obezitesinin önlenmesinde önemli rol oynayabileceğinin altı çizilmiştir. Grimes et al. (8) 2-16 yaş grubundan 4283 katılımcı ile yaptıkları çalışmada, şekerli içecek tüketiminin \%62 oranında olduğunu; yaş, cinsiyet, sosyo-ekonomik durum ve enerji gibi karıştırıcı faktörlere göre düzeltme yapıldıktan sonra, diyetle alınan tuz miktarının her bir gramının şekerli içecek tüketimini $17 \mathrm{~g}$ arttırdığını bildirmiştir. Aynı araştırmacılar tarafından yapılan başka bir çalışmada 6400 adölesanın diyetle tuz alımlarındaki her $1 \mathrm{~g} /$

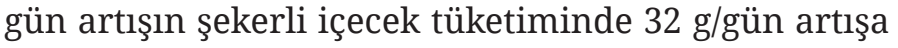
neden olduğu gösterilmiştir. Bu durumun diyetle sodyum alımı ile yüksek enerji alımı arasındaki ilişkinin olası açıklaması olabileceği ileri sürülmüştür (18). Çocuklarda şekerli içecek tüketiminin obezitenin artan prevalansıyla ilişkili olduğunu gösteren çalışmaların ışığında, diyetle tuz alımının toplam sıvı ve şekerli içecek tüketiminin önemli bir belirleyicisi olduğu ve tuz alımının azaltılmasının artan çocukluk çağı obezitesini önlemede önemli bir strateji olabileceği vurgulanmaktadır $(19,20)$.
Yetişkinlerde yapılan çalışmaların sonuçlarının çocuk ve adölesanlarda yapılan çalışmaların sonuçlarına göre daha çelişkili olduğu görülmektedir (21-24). Diyetle akut olarak sodyum alımının içecek tüketimine etkisinin araştırıldığı 58 bireyin dahil edildiği bir çalışmada, tuz eklenmiş yağlı tohum (erkeklerde 3.5-4.4 g tuz alımı, kadınlarda 1.9-3.7 g tuz alımı) tüketiminin aynı miktarda tuz içermeyen yağlı tohum tüketimine kıyasla susama durumu ve sıvı tüketim miktarını etkilemediği bildirilmiştir (21). Sağlıklı yetişkin erkeklerle yapılan randomize kontrollü bir çalışmada 0, 500, 1000, 1500 ve 2000 mg sodyum eklenmiş domates suyu tüketiminden sonra ad libitum test yemeği sirasindaki subjektif susama durumu ve su tüketimi analiz edilmiştir (22). Bu çalışmada, su tüketimi $2000 \mathrm{mg}$ sodyum eklenmiş grupta $500 \mathrm{mg}$ eklenmiş gruba göre anlamlı düzeyde yüksek bulunmasına karşın, kontrol grubuyla karşılaştırıldığında önemli bir fark olmadığı saptanmıştır (22). Uzun dönemli kontrollü koşullarda yapılan bir müdahale çalışmasında ise tuz alımında 6 g/gün artış sonucunda mineralokortikoid ve glikokortikoid düzeylerindeki değişim ile vücut suyunun korunduğu ve sıvı tüketiminin azaldığı rapor edilmiştir (23). Sodyum ve sıvı dengesinin sağlanmasına yönelik mekanizmaların karmaşık olması ve hormonal, metabolik ve sistemik süreçleri içermesi çelişkili sonuçları kısmen açıklamaktadır. Buna karşın, diyetle tuz alımı ve şekerli içecek tüketimi arasındaki ilişkiye yönelik verilerin çoğunluğunun sadece epidemiyolojik çalışmalara dayanması ve yetişkinlere yönelik çalışmaların sayıca az olması neden-sonuç ilişkisinin kurulmasını güçleştirmektedir (24). Ayrıca müdahale çalışmaları dışında yapılan retrospektif ve prospektif çalışmalarda diyetle alınan tuz miktarının saptanmasındaki zorluklar, çoğunlukla besinlere eklenen tuz miktarının analize dahil edilmemesi gibi durumlar, etkilerin gösterilmesini ve çalışmaların doğru yorumlanmasını zorlaştırmaktadır. Bu çerçevede diyetle tuz alımının değerlendirilmesinde kullanılacak daha hassas araçların geliştirilmesi gerekmektedir (3). Diyetle tuz alımı ile şekerli içecek tüketimi arasındaki ilişkinin kanıt düzeyine ulaşabilmesi için iyi tasarlanmış deneysel çalışmalara ihtiyaç duyulmaktadır (24). 
Diyetle Tuz Alımının Yağlı Besin Tüketimi Üzerine Etkisi

Bir besinin beğenilmesinde ve tercih edilmesinde tuz ve şeker, yağdan daha güçlü etkiye sahiptir. $\mathrm{Bu}$ nedenle, besinlerin yağ içeriğinin tek başına arttırılmasının lezzeti arttırmada her zaman etkili olmadiğı, tuz ve/veya şeker içeriği ile birlikte arttırıldığında lezzetin de arttığı bilinmektedir $(25,26)$. Yağın tuz ile oluşturduğu iştah açıcı kombinasyon cips, kraker gibi atıştırmalıklar, çeşitli fast-food besinler ve işlenmiş hazır besinlerde yaygın olarak kullanılmaktadır (26). Bu durum, tuzlu besinlerin aynı zamanda diyetle yağ alımının temel kaynakları olmasına da neden olmaktadır. Ayrıca küreselleşme ve ekonomik büyüme sonucu tüm dünyada işlenmiş besinlere erişimin artması yüksek yağ, tuz ve şeker içeren bu besinlerin tüketiminin fazla olduğu Batı tarzı diyetlerin yaygınlaşmasına neden olmuştur (27). Batı tarzı diyetlerde, günlük alınan tuzun yaklaşık \%75’inin işlenmiş besinlerden geldiği düşünülürse, diyetle tuz alımının işlenmiş besinler üzerinden yağ alımına önemli bir katkı sağlayabileceği öngörülmektedir (Şekil 1).

Son dönemde yağ tüketim miktarı üzerinde yağ tadı duyarlılığının etkili olduğu, yağ duyarlılığı yüksek olan bireylerde diyet yağına karşı daha güçlü tokluk yanıtı oluştuğu ve böylece daha az yağ tüketildiği gösterilmiştir (28). Bu mekanizmada tuzun rolü tartışmalıdır. Yetişkin bireylerde yapılan randomize çapraz tasarımlı bir çalışmada, standart kahvaltının ardından dört farklı içerikte (düşük yağ/düşük tuz, düşük yağ/yüksek tuz, yüksek yağ/düşük tuz, yüksek yağ/yüksek tuz) öğle yemeğinin ad libitum besin alımı üzerine etkisi incelenmiştir (7). Çalışma sonucunda tuz alımının yağ içeriğinden bağımsız olarak besin tüketiminde \%11 oranında artış sağladığı ve yağ duyarlılığı yüksek olan bireylerde yağ aracılı doygunluğa engel olarak yağ tüketimini arttırdığı gösterilmiştir. Bolhuis et al. (26) farklı tuz ve yă̆ konsantrasyonlarında domates çorbası tükettirilen bireylerde, yağ duyarlılığı yüksek olanların daha düşük yağ konsantrasyonlarını tercih ettiklerini ancak bu etkinin yalnızca tuz içermeyen besinlerde görüldüğünü, tuzun yağ duyarlılığını maskelediğini bildirmişlerdir. $\mathrm{Bu}$ çalışmanın aksine aynı araştırmacılar tarafından yapılan bir diğer çalışmada, yağ duyarlılığı ile besinlerin yağ içeriği arasında anlamlı ilişki bulunmasa da, tuz konsantrasyonu arttıkça ilişkinin azaldığı gösterilmiştir (29). Genel olarak, tuz ve yağ içeriği yüksek besinlere olan ilgi yağ tadından daha çok tuzun lezzetlilik üzerindeki güçlü etkisiyle ilişkilendirilmiştir (26).

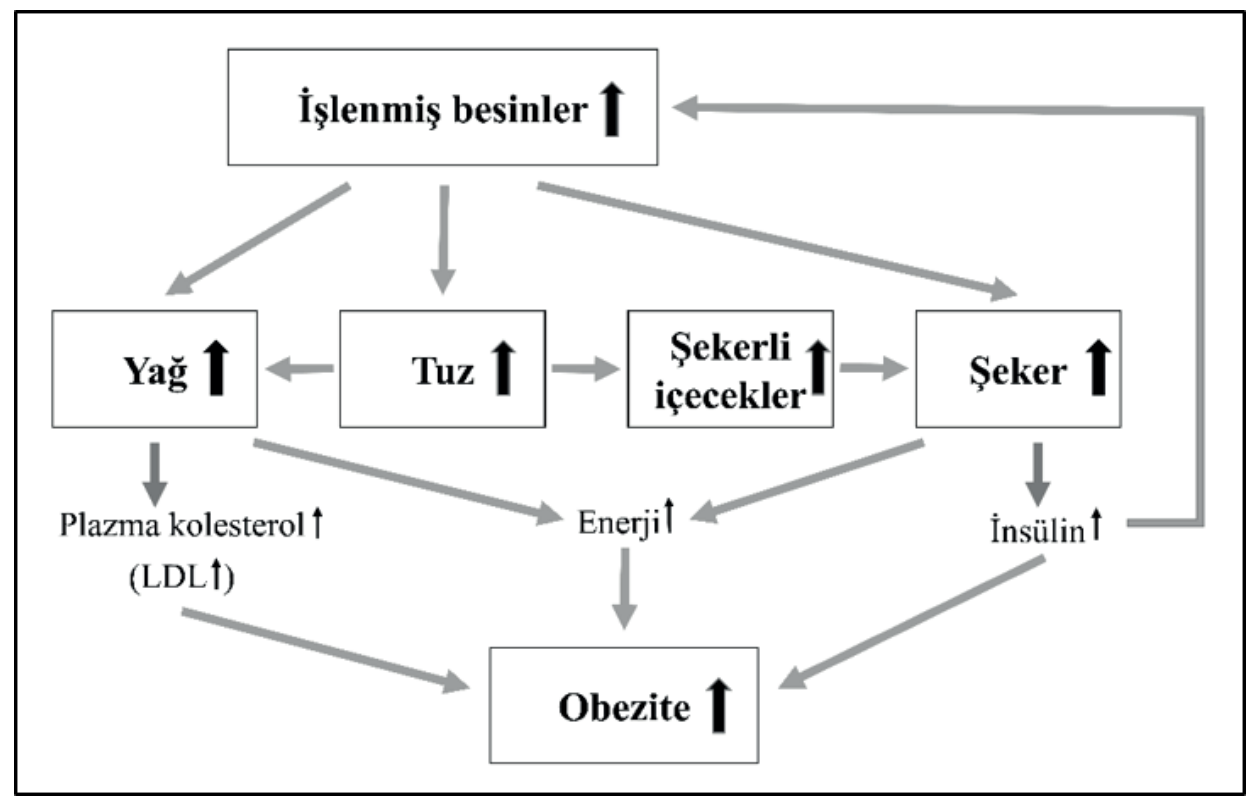

Şekil 1. Tuz, yağ, şeker ve obezite arasındaki potansiyel ilişki (27) (uyarlanmıştır) LDL: Düşük yoğunluklu lipoprotein. 


\section{Diyetle Tuz Alımının Aşırı Besin Tüketimi Üzerine Etkisi}

Bir besinin tercih edilmesi ve/veya hangi miktarda tüketileceği o besinin tuz, yağ ve şeker içeriği ile ilişkilendirilmektedir. Sodyum içeriği yüksek olan besinlerin enerji içeriklerinin genellikle yüksek olduğu ve aşırı yeme davranışını arttırdığı ileri sürülmüştür (30). Tipik olarak yüksek enerjili, besin ögesi açısından fakir, doymuş yağ ve tuz açısından yüksek içeriği olan besinlerin arzu edilebilirliğinin fazla olması aşırı tüketimin nedeni olarak görülmektedir (31). Buna karşın, tuz, şeker ve yağ ile ilgili çalışmaların sayıları karşılaştırıldığında, besinin tuz içeriğinin veya başka bir ifade ile tuzlu tadın besin tüketimi üzerine etkilerinin, besinin şeker veya yağ içeriğine göre literatürde daha az çalışıldığı dikkat çekmektedir (25).

Besinlerin duyusal özellikleri ile diyetle tüketim durumları arasındaki etkileşimlerin daha iyi anlaşılması, tuzun besin tüketimi üzerindeki rolünün incelenmesine olanak sağlamaktadır. Normal ve obez bireylerde temel tatların tercihi ve bu tatlara duyarlılığın farklılık gösterip göstermediğini inceleyen 25 insan çalışmasının dahil edildiği kapsamlı bir derlemede; tatlı, tuzlu, ekşi ve acı tatlar ile obezite durumu arasındaki ilişkiye dair çok az kanıt olduğu bildirilmiştir (32). Çocuklarda sadece tuzlu tat için diyetle besin tüketimi ve vücut ağırlık durumu arasında önemli pozitif ilişki olduğu rapor edilmiştir. Günlük tüketilen tüm yiyecek ve içecekler dahil edilerek şeker, yağ ve tuz açısından diyetin toplam duyusal profilinin hesaplandiğı bir çalışmada ise diyetin tuzluluğu ile günlük enerji alımı arasında güçlü bir pozitif ilişki olduğu gösterilmiştir (33). Tuz, yağ ve şeker içeriğinin lezzeti arttırarak besin tüketimi üzerinde oluşturduğu değişiklikleri değerlendirmeyi amaçlayan, 74 çocuğun dahil edildiği bir çalışmada, standart öğle yemeğinin yanında verilen farklı miktarda tuz içeren $(\% 0.0$, $\% 0.6$ ve \%1.2) taze fasulye ve makarnanın ad libitum tüketimi kaydedilmiş ve artan tuz düzeyinin hedef besinlerin tüketimini arttırdığı gösterilmiştir (34). Aynı araştırmacılar, 8-11 yaş arası çocuklarda da benzer etkileri göstererek, besin alımını tetikleyen faktörlerden birinin çocukların tuz içeriği zengin besinleri tercih etmeleri olduğunu rapor etmişlerdir (35). Çocukların yetişkinlere göre daha yüksek tatlı ve tuzlu tatları tercih ettiği, tatlı ve tuzlu tat tercihi ile diyetle besin alımı arasında doğrusal ilişki olduğu gösterilmiştir (36). Atıştırmalık besin tüketim miktarı ve içeriğinin obezite üzerindeki etkisinin incelendiği bir çalışmada, obez çocukların obez olmayanlara göre atıştırmalık besin tüketim sıklığının farklı olmadığı ancak özellikle tuzlu atıştırmalıkları daha fazla tükettikleri bildirilmiştir (37). Dikkat çekici bir şekilde, enerji yoğunluğundan bağımsız olarak, tuzlu atıştırmalık tüketiminde haftalık her bir porsiyon artışın obezite riskini \%2 oranında arttırdığı rapor edilmiştir.

Yetişkinlerle yürütülen, duyusal özelliklerin doygunluk ve besin tüketimi üzerindeki rolüne yönelik yapılan çalışmaların sonuçları çelişkilidir (38-40). Tuz tadı hassasiyetinin bir göstergesi olan tuz eşik değeri ölçülen yetişkin bireylere, sodyum içeriği (40 mg, 120 mg, 170 mg ve 220 mg sodyum/100 g) farklı patates mücveri tükettirilerek tuz eşik değerinin algılanan tuzluluk, beğeni ve mücver tüketim miktarı ile ilişkisinin incelendiği çalışmada tuz eşiğinin besin tercihini ve tüketim miktarını etkilemediği gösterilmiştir (38). Başka bir çalışmada ise, her bir birey için ideal tuz yoğunluğu saptanmış ve sonrasında düşük ve yüksek tuz yoğunluklu domates çorbası tüketiminin ad libitum tüketim miktarı, iştah durumu ve tüketim sonrası hedonik skorlara etkisi değerlendirilmiştir (39). Bu çalışmada yüksek veya düşük tuz yoğunluğunun ad libitum besin tüketimi, yeme oranı, iştah ve hedonik skorlarda önemli bir değişikliğe neden olmadığı gösterilmiş; bu durum lezzet benzer olduğunda tuz yoğunluğunun besin tüketimi ve doygunluk üzerinde önemli etkisinin olmadığı şeklinde açıklanmıştır (39). Aynı araştırma ekibi tarafından yapılan benzer bir çalışmada da, farklı tuz yoğunluklu domates çorbasının birinci kap veya ikinci kap yemek olarak servis edildiğinde ad libitum besin tüketimine ve çorbadan sonraki besin seçimine etkileri incelenmiştir. Bu çalışmada çorbanın servis sırasının ad libitum besin tüketimini 
etkilemediği, çorbanın tuz yoğunluğunun daha sonraki besin seçiminin tatlı veya tuzlu olma durumunu değiştirmediği gösterilmiştir (40). Genç erkek bireylerin dahil edildiği randomize kontrollü bir çalışmada ise $71 \mathrm{mg}, 740 \mathrm{mg}$ ve $1480 \mathrm{mg}$ sodyum içeren kuru fasulye tüketiminden 2 saat sonra ad libitum pizza tüketim miktarı incelenmiş, $740 \mathrm{mg}$ sodyum içeren kuru fasulye tüketiminden sonra 1480 mg içerene göre 116 kkal eşdeğerinde daha fazla pizza tüketildiği saptanarak, akut olarak alınan sodyumun kısa dönem subjektif doygunluk ve besin alımı üzerine etkisinin olmadığı yorumu yapılmıştır (22).

\section{SONUÇ VE ÖNERILLER}

Batı tarzı diyetlerde özellikle işlenmiş besin tüketimindeki artışa paralel olarak diyetle tuz ve sodyum alımı önerilen miktarların çok üstüne çıkmaktadır. Diyetle yüksek tuz alımı ve neden olduğu sağlık sorunları tüm dünyada öncelikli halk sağlığı sorunları arasında kabul edilmektedir. Diyetle artmış tuz alımının hipertansiyon başta olmak üzere kardiyovasküler hastalıklar, inme, böbrek hastalıkları, osteoporoz ve bazı kanser türleri için önemli bir risk etmeni olduğu uzun ylllardır bilinmektedir. Son ylllarda yüksek tuz alımının diğer besinlerin tercih ve tüketimlerinde değişikliklere neden olarak obezite ve ilişkili hastalıkların artan prevalansında rol oynayabileceği önerilmektedir. Özellikle çocukluk döneminde, diyetle tuz alımının toplam sivı ve şekerli içecek tüketiminin önemli bir belirleyicisi olduğu ve bu durumun susama mekanizmalariyla açıklandığı görülmektedir. Ek olarak, tuzlu besinlerin aynı zamanda yüksek yağ ve enerji içerdiği, iştahı uyararak besin tüketimini arttırdığı ve aşırı yeme davranışlarına neden olabildiği de gösterilmiştir. Ancak özellikle yetişkinlerde yapılan çalışmalardan elde edilen sonuçların çelişkili olması, ileri sürülen etkilerin olası mekanizmalarına yönelik kanıtlara gereksinimi artırmaktadır. $\mathrm{Bu}$ konuda yapılan çalışmalardaki en önemli sınırlılıklardan birinin diyetle tuz alımının değerlendirilmesindeki güçlük olduğu düşünülmektedir. Yapılacak yeni çalışmalarda diyetle tuz alımı değerlendirilirken, besinlerin sodyum içeriğinin yanında besinlere pişirme sırasında ve sofrada eklenen tuz miktarının da saptanmasını sağlayan daha hassas araçların kullanılması beklenen hipotezlerin doğrulanabilmesi açısından önem taşımaktadır. Ayrıca, ilave yağ, şeker ve tuz içeren işlenmiş besinlerin daha düşük üretim maliyeti, uzun raf ömrü ve artan lezzeti besin sanayindeki arzın artmasıyla sonuçlanmaktadır. Diyetle tuz alımının büyük oranda işlenmiş besinlerden geldiğini gösteren çalışmaların ışığında, toplulukların sodyum alımını azaltmak için en önemli müdahalenin bu ürünlerin daha düşük sodyum içerecek şekilde yeniden formüle edilmesi olduğu düşünülmektedir.

Çıkar çatışması - Conflict of interest: Yazarlar çıkar çatışması olmadığın beyan ederler. - The authors declare that they have no conflict of interest.

\section{KAYNAKLAR}

1. World Health Organization. Salt reduction fact sheet. June 30, 2016. Available at: http://www.who.int/newsroom/fact-sheets/detail/salt-reduction. Accessed June 15, 2019.

2. He FJ, MacGregor GA. A comprehensive review on salt and health and current experience of worldwide salt reduction programmes. J Hum Hypertens. 2009;23(6):363.

3. Moosavian SP, Haghighatdoost F, Surkan PJ, Azadbakht L. Salt and obesity: a systematic review and metaanalysis of observational studies. Int J Food Sci Nutr. 2017;68(3):265-77.

4. Hu G, Jousilahti P, Peltonen M, Lindström J, Tuomilehto J. Urinary sodium and potassium excretion and the risk of type 2 diabetes: a prospective study in Finland. Diabetologia. 2005;48(8):1477-83.

5. Fonseca-Alaniz MH, Brito LC, Borges-Silva CN, Takada J, Andreotti S, Lima FB. High dietary sodium intake increases white adipose tissue mass and plasma leptin in rats. Obesity. 2007;15(9):2200-8.

6. Lanaspa MA, Kuwabara M, Andres-Hernando A, Li $\mathrm{N}$, Cicerchi $\mathrm{C}$, Jensen $\mathrm{T}$, et al. High salt intake causes leptin resistance and obesity in mice by stimulating endogenous fructose production and metabolism. Proc Natl Acad Sci. 2018;115(12):3138-43.

7. Bolhuis DP, Costanzo A, Newman LP, Keast RS. Salt promotes passive overconsumption of dietary fat in 
humans. J Nutr. 2015;146(4):838-45.

8. Grimes CA, Riddell LJ, Campbell KJ, Nowson CA. Dietary salt intake, sugar-sweetened beverage consumption, and obesity risk. Pediatrics. 2013;131(1):14-21.

9. Duffey KJ, Popkin BM. High-fructose corn syrup: is this what's for dinner? Am J Clin Nutr. 2008;88(6):1722-32.

10. Johnson RJ, Segal MS, Sautin Y, Nakagawa T, Feig DI, Kang DH, et al. Potential role of sugar (fructose) in the epidemic of hypertension, obesity and the metabolic syndrome, diabetes, kidney disease, and cardiovascular disease. Am J Clin Nutr. 2007;86(4):899-906.

11. World Health Organization. Guideline: sugars intake for adults and children. Geneva: 2015. p.49.

12. McKinley MJ, Johnson AK. The physiological regulation of thirst and fluid intake. Physiology. 2004;19(1):1-6.

13. He FJ, Markandu ND, Sagnella GA, MacGregor GA. Effect of salt intake on renal excretion of water in humans. Hypertension. 2001;38(3):317-20.

14. Collison KS, Zaidi MZ, Subhani SN, Al-Rubeaan K, Shoukri M, Al-Mohanna FA. Sugar-sweetened carbonated beverage consumption correlates with BMI, waist circumference, and poor dietary choices in school children. BMC Public Health. 2010;10(1):234.

15. Alexy U, Cheng G, Libuda L, Hilbig A, Kersting M. 24h-Sodium excretion and hydration status in children and adolescents-results of the DONALD Study. Clin Nutr. 2012;31(1):78-84.

16. Gonçalves C, Abreu S, Padrão P, Pinho O, Graça P, Breda $\mathrm{J}$, et al. Association between sodium excretion and hydration status by free water reserve: a cross-sectional analysis in adolescents. BMC Nutrition. 2015;1(1):17.

17. He FJ, Marrero NM, MacGregor GA. Salt intake is related to soft drink consumption in children and adolescents: a link to obesity? Hypertension. 2008;51(3):629-34.

18. Grimes CA, Wright JD, Liu K, Nowson CA, Loria CM. Dietary sodium intake is associated with total fluid and sugar-sweetened beverage consumption in US children and adolescents aged 2-18 y: NHANES 2005-2008. Am J Clin Nutr. 2013;98(1):189-96.

19. Ludwig DS, Peterson KE, Gortmaker SL. Relation between consumption of sugar-sweetened drinks and childhood obesity: a prospective, observational analysis. Lancet. 2001;357(9255):505-8.

20. James J, Thomas P, Cavan D, Kerr D. Preventing childhood obesity by reducing consumption of carbonated drinks: cluster randomised controlled trial. BMJ. 2004;328(7450):1237.

21. Leshem M. Does salt increase thirst? Appetite. 2015;85:70-5.

22. Nunez MF, Mollard RC, Luhovyy BL, Wong CL, Anderson
GH. Acute sodium ingestion has no effect on short-term food and water intake, subjective appetite, thirst, or glycemic response in healthy young men. Appl Physiol Nutr Metab. 2013;38(7):746-52.

23. Rakova N, Kitada K, Lerchl K, Dahlmann A, Birukov A, Daub S, et al. Increased salt consumption induces body water conservation and decreases fluid intake. J Clin Invest. 2017;127(5):1932-43.

24. Ray EC, Kleyman TR. An increasingly complex relationship between salt and water. Am J Kidney Dis. 2017;70(5):599-601.

25. Méjean C, Deglaire A, Kesse-Guyot E, Hercberg S, Schlich $\mathrm{P}$, Castetbon K. Association between intake of nutrients and food groups and liking for fat (The Nutrinet-Sante Study). Appetite. 2014;78:147-55.

26. Bolhuis DP, Newman LP, Keast RS. Effects of salt and fat combinations on taste preference and perception. Chem Senses. 2015;41(3):189-95.

27. He FJ, MacGregor GA. Salt and sugar: their effects on blood pressure. Pflugers Arch. 2015;467(3):577-86.

28. Stewart JE, Feinle-Bisset C, Golding M, Delahunty C, Clifton PM, Keast RS. Oral sensitivity to fatty acids, food consumption and BMI in human subjects. Br J Nutr. 2010;104(1):145-52.

29. Bolhuis DP, Costanzo A, Keast RS. Preference and perception of fat in salty and sweet foods. Food Qual Prefer. 2018;64:131-7.

30. Grimes CA, Bolhuis DP, He FJ, Nowson CA. Dietary sodium intake and overweight and obesity in children and adults: a protocol for a systematic review and metaanalysis. Syst Rev. 2016;5(1):7.

31. Kearney J. Food consumption trends and drivers. Philos Trans R Soc Lond B Biol Sci. 2010;365(1554):2793-807.

32. Cox DN, Hendrie GA, Carty D. Sensitivity, hedonics and preferences for basic tastes and fat amongst adults and children of differing weight status: A comprehensive review. Food Qual Prefer. 2016;48:359-67.

33. Cox DN, Hendrie GA, Lease HJ, Rebuli MA, Barnes M. How does fatty mouthfeel, saltiness or sweetness of diets contribute to dietary energy intake? Appetite. 2018;131:36-43.

34. Bouhlal S, Issanchou S, Nicklaus S. The impact of salt, fat and sugar levels on toddler food intake. Br J Nutr. 2011;105(4):645-53.

35. Bouhlal S, Chabanet C, Issanchou S, Nicklaus S. Salt content impacts food preferences and intake among children. PLoS One. 2013;8(1):e53971.

36. Mennella JA, Finkbeiner S, Lipchock SV, Hwang L-D, Reed DR. Preferences for salty and sweet tastes are elevated and related to each other during childhood. 
PLoS One. 2014;9(3):e92201.

37. Maffeis C, Grezzani A, Perrone L, Del Giudice EM, Saggese G, Tato L. Could the savory taste of snacks be a further risk factor for overweight in children? J Pediatr Gastr Nutr. 2008;46(4):429-37.

38. Lucas L, Riddell L, Liem G, Whitelock S, Keast R. The influence of sodium on liking and consumption of salty food. J Food Sci. 2011;76(1):S72-S6.
39. Bolhuis DP, Lakemond CM, de Wijk RA, Luning PA, de Graaf C. Effect of salt intensity on ad libitum intake of tomato soup similar in palatability and on salt preference after consumption. Chem Senses. 2010;35(9):789-99.

40. Bolhuis DP, Lakemond CM, de Wijk RA, Luning PA, de Graaf C. Effect of salt intensity in soup on ad libitum intake and on subsequent food choice. Appetite. 2012;58(1):48-55. 